Check for updates

Cite this: RSC Adv., 2017, 7, 31018

Received 20th February 2017

Accepted 22nd May 2017

DOI: $10.1039 / \mathrm{c} 7 \mathrm{ra02105d}$

rsc.li/rsc-advances

\title{
Evaluation of biodegradability and biotoxicity of surfactants in soil
}

\author{
Guixiang Li, ${ }^{\text {ab }}$ Guihong Lan, (D) *ab Yongqiang Liu, ${ }^{c}$ Chen Chen, ${ }^{\text {ab }}$ Lin Lei, $^{\text {ab }}$ Jiao Du, ${ }^{\text {ab }}$ \\ Yingchun Lu, ${ }^{\text {ab }}$ Qiang Li, ${ }^{d}$ Guoyong Du ${ }^{\text {ab }}$ and Jihong Zhang ${ }^{\mathrm{e}}$
}

In this study, the biodegradability and biotoxicity of four surfactants, i.e. modified heterogeneous alcohol ether with an 8-12 carbon alkylic chain, fatty acid methyl ester ethoxylates, Tween-80 and rhamnolipid (a kind of biosurfactant), under natural soil conditions were investigated. Batch experiments of degradation with an initial concentration of surfactants of $120 \mathrm{mg} \mathrm{kg}^{-1}$ in soil were carried out at room temperature varying from $15{ }^{\circ} \mathrm{C}$ to $22{ }^{\circ} \mathrm{C}$. The concentrations of surfactants over time were measured and metabolites of the surfactants were characterized by gas chromatography-mass spectrometry. In addition, the amount of microorganisms in soil over time was measured by using agar plates. The results showed that fatty acid methyl ester ethoxylates had the highest biodegradation rate followed by rhamnolipid, Tween-80 and modified heterogeneous alcohol ether. A biotoxicity assay based on a photobacterium revealed that these surfactants had low toxicity. It is concluded that the fatty acid methyl ester ethoxylates are the most environmentally friendly surfactants among the four surfactants studied.

\section{Introduction}

A surfactant is a kind of substance containing hydrophobic and hydrophilic groups, which is capable of decreasing the surface tension between water and air. Owing to their unique characteristic, surfactants have been extensively applied in our daily lives, such as in washing detergents and by the food industry. ${ }^{1}$

In addition, a great amount of surfactants was used in the oil industry, such as SDS, Brij 35, and NEPOn, ${ }^{2-4}$ to wash crude oilcontaminated soil to remove the most of the oil or organic contaminants. Nevertheless, the most common use of surfactants was bioremediation in several environmental fields. The use of surfactants as enhancers for the removal of heavy metals ${ }^{5,6}$ and organic contaminations, such as ethylbenzene, DDT and polycyclic aromatic hydrocarbons, ${ }^{6-8}$ has been widely reported.

The worldwide production of surfactants reached 1.78 million tons in 2015, with an annual increasing rate increase of $6 \%$ predicted.

\footnotetext{
${ }^{a}$ Key Laboratory of Oil \& Gas Applied Chemistry of Sichuan Province, Southwest Petroleum University, No. 8 Xindu Avenue, Xindu District, Chengdu 610500, PR China. E-mail: guihonglan416@sina.com; Fax: +86 02883037306; Tel: +86 02883037306

${ }^{b}$ College of Chemistry and Chemical Engineering, Southwest Petroleum University, Chengdu 610500, PR China

${ }^{c}$ Faculty of Engineering and the Environment, University of Southampton, Southampton SO17 1BJ, UK

${ }^{d}$ Development and Application of Rural Renewable Energy, Ministry of Agriculture, PR China

${ }^{e}$ Xinjiang Oilfield Company, No. 1 Gas Production Plant, PR China
}

Because of the extensive production and consumption of these compounds, some parts of them can get into the environment via the discharge of wastewater after their primary use in aqueous solutions. The compounds which cannot be easily degraded in the environment would accumulate in sediments and soil and leak into groundwater and wastewater. ${ }^{9}$ As reported, after application these chemicals are disposed of down the drain to sewers, where it is estimated that $50 \%$ by volume is degraded, with $25 \%$ absorbed as suspended solids and 25\% dissolved. ${ }^{10}$ Different surfactants vary in their behavior and fate in the environment.

To overcome the pollution problem caused by surfactants, a broad range of chemical and biological methods have been applied to mitigate their effects. ${ }^{11,12}$ The most common chemical treatment of a surfactant is adsorption by means of activated carbon and advanced oxidation such as the $\mathrm{H}_{2} \mathrm{O}_{2}$ /UV-C process and photo-Fenton processes which have been applied in degradation treatments of surfactants in higher concentration. ${ }^{\mathbf{1 3 , 1 4}}$ However, for lower concentrations, chemical treatments not only operate poorly with high cost but also cause secondary pollutants, such as $\mathrm{Fe}^{2+}$ in the photo-Fenton oxidation treatment process. Therefore, the biodegradation treatment of surfactantcontaminated soil was considered to be a promising and costeffective method for degrading surfactants when environmental conditions were optimal for performing biodegradation reactions. In addition, surfactants as a species of organic compounds can be used as a carbon source for the growth of various kinds of bacteria. Linear alkylbenzene sulphonic acid can be easily eliminated in natural conditions, with a half-life 
Table 1 CMC of each surfactant and the corresponding surface tension

\begin{tabular}{lll}
\hline Surfactant & $\begin{array}{l}\text { CMC } \\
\left(\mathrm{mg} \mathrm{L}^{-1}\right)\end{array}$ & $\begin{array}{l}\text { Surface tension } \\
\left(\mathrm{mN} \mathrm{m}^{-1}\right)\end{array}$ \\
\hline MHAE & 14 & 29.5 \\
FMEE & 80 & 33.6 \\
Rhamnolipid & 15 & 31.5 \\
Tween-80 & 14 & 37.8 \\
\hline
\end{tabular}

time range from 7 to 33 days, reported by John Jensen in $1999 .{ }^{15}$ It has also been demonstrated that microorganisms can consume cationic surfactant quaternary ammonium compounds under aerobic conditions. However, the degradation process was complex and depended on the structure of the carbon chain. ${ }^{16}$ The non-ionic surfactant branched chain nonyl phenol ethoxylate can be degraded by an ozone-induced biodegradability process. ${ }^{17}$ Considering the contamination caused by surfactants and the biodegradability potential of some types of surfactants, it is better to evaluate the degradability and toxicity of surfactants before they are put into applications to minimize their negative effects on the environment. In this study, we investigated one type of biosurfactant represented by rhamnolipid and three widely used synthetic nonionic surfactants. The synthetic surfactants are modified heterogeneous alcohol ether (MHAE) with the structure of a fatty alcohol containing several oxyethyl groups, fatty alcohol methyl esters of ethoxylate (FMEE) consisting of a fatty acid methyl ester, and Tween-80 whose main component is the sorbitol ester. All of them have a surface tension value, such as $29.5 \mathrm{mN} \mathrm{m}^{-1}, 33.6 \mathrm{mN} \mathrm{m}^{-1}$ and $37.8 \mathrm{mN}$ $\mathrm{m}^{-1}$, respectively, at each of their critical micelle concentrations (CMC), which is relatively lower than most other types of surfactants (Table 1). Thus, they are widely used in different areas. However, the biodegradation and toxicity information about these surfactants is lacking, which results in a surfactant selection based only on their function rather than on both function and environmental and environmental protection. It is well known that the discharge of surfactant contaminated water may cause serious damage to the water body and soil environment around us. An excess of surfactant can change the microbial community of the surroundings, and its toxicity may affect the growth of plants.

This research aimed to evaluate the potential bioconversion process and the biodegradation mechanism of three synthetic nonionic surfactants and rhamnolipid in soil. The environmental effect that each surfactant may have on its surroundings has also been determined to predict its safety and to avoid the potential risk that surfactants may bring about in the future.

\section{Materials and methods}

\section{Chemicals preparation}

All of the reagents used in this work were analytical grade unless specially mentioned. The modified heterogeneous alcohol ether (MHAE), fatty alcohol methyl esters of ethoxylate (FMEE) and
Tween-80 with 98\% purity were supplied by Kelong (Chengdu. China). The rhamnolipid used in this research was produced by Pseudomonas SWP-4. ${ }^{18}$

Table 1 lists the critical micelle concentration (CMC) and the surface tension at CMC of each surfactant. And deionized water $(>18.25 \mathrm{Mcm})$ was used to make the solutions. Stock solutions of each of the studied compounds at a concentration of $1000 \mathrm{mg}$ $\mathrm{L}^{-1}$ were prepared in deionized water and stored at $4{ }^{\circ} \mathrm{C}$.

Working solutions were diluted with the stock solutions in deionized water according to different concentration levels.

\section{Characterization of soil samples}

Soil samples were collected from agricultural land at latitude $30.84^{\circ}$ north, and longitude $104.19^{\circ}$ east in China, in which all the surroundings were without any pollution sources. Before the experiment, soil was air dried and sieved through a $2 \mathrm{~mm}$ screening mesh. The collected air-dried soil was put in a refrigerator at a temperature of $-4{ }^{\circ} \mathrm{C}$ until analysis. Prior to the application of the soil, its properties, including $\mathrm{pH}$, total potassium, total phosphorus, total organic carbon content (TOC) and total nitrogen (TN), were investigated and the results are shown in Table 2.

\section{Biodegradation test of surfactants in soil}

Batch experiments were carried out in $3 \mathrm{~L}$ pots with $2.5 \mathrm{~kg}$ of soil and $120 \mathrm{~mL}$ of surfactant solution with a concentration of $1000 \mathrm{mg} \mathrm{L}^{-1}$, resulting in $120 \mathrm{mg}$ of surfactant per kilogram of dry soil. All of these soil samples dosed with surfactants were homogenized by hand before and after being used to fill pots to ensure a homogeneous distribution of surfactants in the soil. We firstly investigated the degradation rates of four surfactants in the collected soil. Each surfactant solution was added into soil in duplicate. The other factors were adjusted as follows: the room temperature in this period varied from $15{ }^{\circ} \mathrm{C}$ to $22{ }^{\circ} \mathrm{C}$. In order to archive a stable condition, deionized water was needed to maintain the moisture content at around 30\%. The biodegradation experiments were carried out for a period of 75 days. Samples were collected periodically for analysis.

\section{Monitoring microorganism amount during the surfactant biodegradation period}

To investigate the influence of surfactants on microorganisms in the soil, the number of microorganisms was counted based

Table 2 The main characteristics of soil used in this work

\begin{tabular}{lc}
\hline Parameter & Value \\
\hline pH & 6.89 \\
Coars sand (\%) & 39.1 \\
This sand (\%) & 4.0 \\
Silt (\%) & 5.3 \\
Clay (\%) & 51.5 \\
Total phosphorus $\left(\% \mathrm{P}_{2} \mathrm{O}_{5}\right)$ & 0.14 \\
Total organic carbon $(\%)$ & 1.15 \\
Nitrogen $(\%$ TKN) & 0.17 \\
Total potassium $\left(\% \mathrm{~K}_{2} \mathrm{O}\right)$ & 0.43
\end{tabular}


on the method reported by Jackson. ${ }^{19} 2.5$ gram of soil sample was placed into a centrifuge tube. Sterilized physiological saline $(20 \mathrm{~mL})$ was added into the centrifuge tube and the tube was shaken in a shaker for $10 \mathrm{~min}$ at a speed of $200 \mathrm{rpm}$. The water extract was serially diluted and then $100 \mu \mathrm{L}$ of the higher dilutions $\left(10^{-2}\right.$ to $\left.10^{-5}\right)$ were plated on nutrient agar which was made up of peptone, beef extract, deionized water, sodium chloride and agar. After incubation over 48 hours at $35{ }^{\circ} \mathrm{C}$, independent colonies which had emerged in the cultures were counted.

\section{Analysis of surfactants and metabolites}

All four surfactants were extracted from soil samples by sonication-assisted extraction, as described in a previously reported method. ${ }^{20}$ The concentrations of nonionicsurfactants were measured by the $\mathrm{KI}-\mathrm{I}_{2}$ spectrophotometric method because of the color reaction of nonionic surfactant and $\mathrm{KI}-\mathrm{I}_{2}{ }^{21}$ The concentration of biosurfanctant rhamnolipid was determined by the anthrone-sulfuric acid colorimetric method which based on the color reaction between glycolipid and anthrone-sulfuric acid. ${ }^{22,23}$ The metabolites in soil were detected by gas chromatography-mass spectrometry (GC-MS), and solid-phase extraction (SPE) of surfactants was adopted for the concentration and purification of samples for GC-MS analysis, according to the method described by Castillo et $a .^{24}$ The silylation derivation process was carried out by adding a mixture of ethyl acetate and BSTFA/TMCS (99:1, $\mathrm{v} / \mathrm{v}$ ) and then heating at $60^{\circ} \mathrm{C}$ for 30 minutes before the GC-MS procedure. ${ }^{25}$ Once the derivation process was complete, $1 \mu \mathrm{L}$ of the reaction mixture was injected into an Agilent gas chromatography-mass spectrometer (GC-MS) (7890A/ 5975C, USA) without splitting. The study of all these extracts was conducted by the same temperature programming: the initial temperature was $120{ }^{\circ} \mathrm{C}$; then it was raised at a rate of $15{ }^{\circ} \mathrm{C} \min ^{-1}$ to $230{ }^{\circ} \mathrm{C}$; a second ramp was then applied at $30{ }^{\circ} \mathrm{C} \min ^{-1}$ to $260{ }^{\circ} \mathrm{C}$, at which it was maintained for 8 minutes.

\section{Acute toxicity assay}

The acute toxicity of all the surfactants was assayed by a photobacterium, using the method reported by Chongjian Tang. ${ }^{11}$ $1000 \mathrm{mg} \mathrm{L}^{-1}$ of stored solutions of surfactants were diluted 5 to 20 times. At the same time, a preparation for the determination of the toxicity of soil contaminated with surfactant was obtained by dissolving it into deionized water at the rate $1: 1(\mathrm{w} / \mathrm{w})$. Samples were analyzed according to the method of Jiao. ${ }^{12}$ And $10 \mu \mathrm{L}$ of stored Photobacterium phosphereum solution were added to each of the treated samples, and the luminous power of these samples was measured by a DXY-2 instrument (DXY-2, Institute of Soil Science, Chinese Academy of Sciences, Nanjing, China). The relative luminosity $(X)$ was calculated according to eqn (1):

$$
X(\%)=\frac{L_{\text {sample }}}{L_{\text {blank }}} \times 100 \%
$$

where $L$ is the luminous quantity.

\section{Results and discussion}

\section{Characterization of the soil}

From Table 2, it can be inferred that the soil was a loamy soil type, with a clay content of $51.5 \%$, coarse sand: $39.1 \%$, thin sand: $4.0 \%$, silt: $5.3 \%$ and organic carbonate: $1.15 \%$. The soil itself was enriched with organic compounds, which were mainly hexadecanoic acid, butyric acid, 4-methoxy, octadecanoic acid, hexadecanoic acid and propyl ester, as listed in Table 3. The GCMS profiles are shown in Fig. 1.

\section{Bacteria growth in surfactant contaminated soils}

Added surfactants could be an additional source of carbon for bacteria in the soils. The growth characteristics of aerobic bacteria in soil contaminated by different surfactants were investigated. As shown in Fig. 2, the growth profiles with surfactants and the control sample showed a similar pattern. Firstly, all of them underwent a latent phase for around 10 days, and the amount of bacteria was not statistically significant in the first 10 days. Subsequently, after two weeks' incubation, it can be observed that the highest CFU value found in the soil with added FMEE (5.6 in $10^{8} \mathrm{CFU} \mathrm{g}^{-1}$ ) on the $15^{\text {th }}$ day and the time point for the highest $\mathrm{CFU}$ value in the soil was also earlier than for the others. Under the same surfactant concentration, bacteria can gain a relatively quicker growth in the FMEE environment, attaining maximum growth for 30 days and then

Table 3 Main compounds detected by GC-MS in the control soil

Sample

number

$1 \quad$ Hexadecanoic acid, trimethylsilyl ester

2 Butyric acid, 4-methoxy-, trimethylsilyl ester

3 Octadecanoic acid, trimethylsilyl ester

4 1,8-Octanediylbis(trimethylsilane)

$5 \quad$ Hexadecanoic acid, 2,3-bis[(trimethylsilyl)oxy]propyl

6

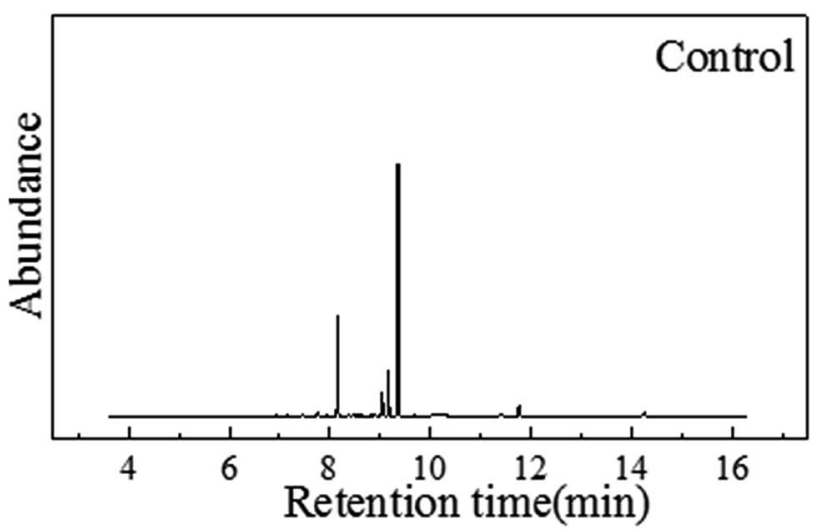

Fig. 1 GC-MS profiles of the control sample. 


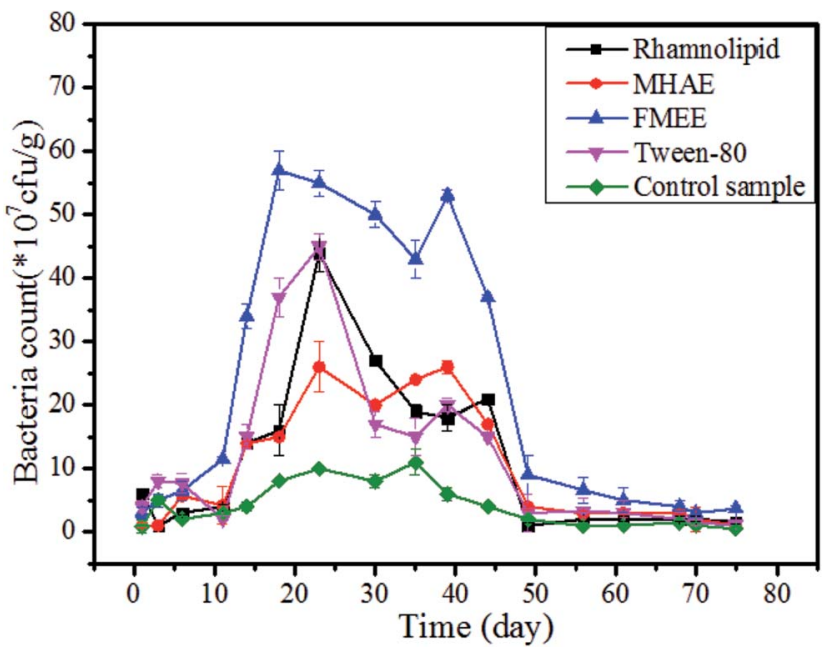

Fig. 2 Bacterial growth profile in soil contaminated by different surfactants during the degradation period, "control" means the soil without a surfactant.

declining. After almost the $35^{\text {th }}$ day, the bacteria count rose a little all of a sudden. This may explained by secondary growth, because the bacteria use other substances as nutrients. The CFU values in soil with added rhamnolipid, MHAE and Tween-80 have the same tendency but at a much lower level.

\section{Surfactant degradation in the soils}

It can be seen from Fig. 3(a) that, after surfactants had been applied onto the soil, the initial concentration of FMEE, MHAE, rhamnolipid and Tween-80 in the soils were $103.29 \mathrm{mg} \mathrm{kg}{ }^{-1}$, $110.5 \mathrm{mg} \mathrm{kg}^{-1}, 116.45 \mathrm{mg} \mathrm{kg}^{-1}$ and $102.55 \mathrm{mg} \mathrm{kg}^{-1}$, respectively. At the beginning of the experiment, the concentration of MHAE was lower than the added concentration, namely, $120 \mathrm{mg}$ $\mathrm{kg}^{-1}$. This indicated that MHAE was adsorbed into the soil more easily than the others. Finally, the concentrations of these surfactants decreased to $2.5 \mathrm{mg} \mathrm{kg}^{-1}, 10.35 \mathrm{mg} \mathrm{kg}^{-1}, 6.34 \mathrm{mg}$ $\mathrm{kg}^{-1}$ and $6.37 \mathrm{mg} \mathrm{kg}{ }^{-1}$, respectively, after 75 days of the degradation process. The rate for FMEE is $6.4 \mathrm{mg}$ ( $\mathrm{kg}$ day) $)^{-1}$ faster than for the others in the first 15 days, which may because of the increase in the number of microorganisms and greater microbial population in this period. Rhamnoplid reached the same relative degradation rate 25 days later. Thirty days later, the decrease in degradation rate may be because of the degradation-resistant group in the surfactants and also a decrease in the number of microorganisms.

\section{Metabolites in surfactants biodegradation process}

Metabolites in MHAE degradation process over time. After the MHAE solution was applied to the soil, the initial concentration was measured. Moreover, the concentration declined dramatically in the first thirty days, and almost reached its lowest concentration of $8.35 \mathrm{mg} \mathrm{kg} \mathrm{kg}^{-1}$ in the degradation process. As shown in Fig. 4, the GC-MS of all the soil samples collected in the first day, the $30^{\text {th }}$ day and the $75^{\text {th }}$ day were detected under the same conditions. And Table 4 lists the (a)
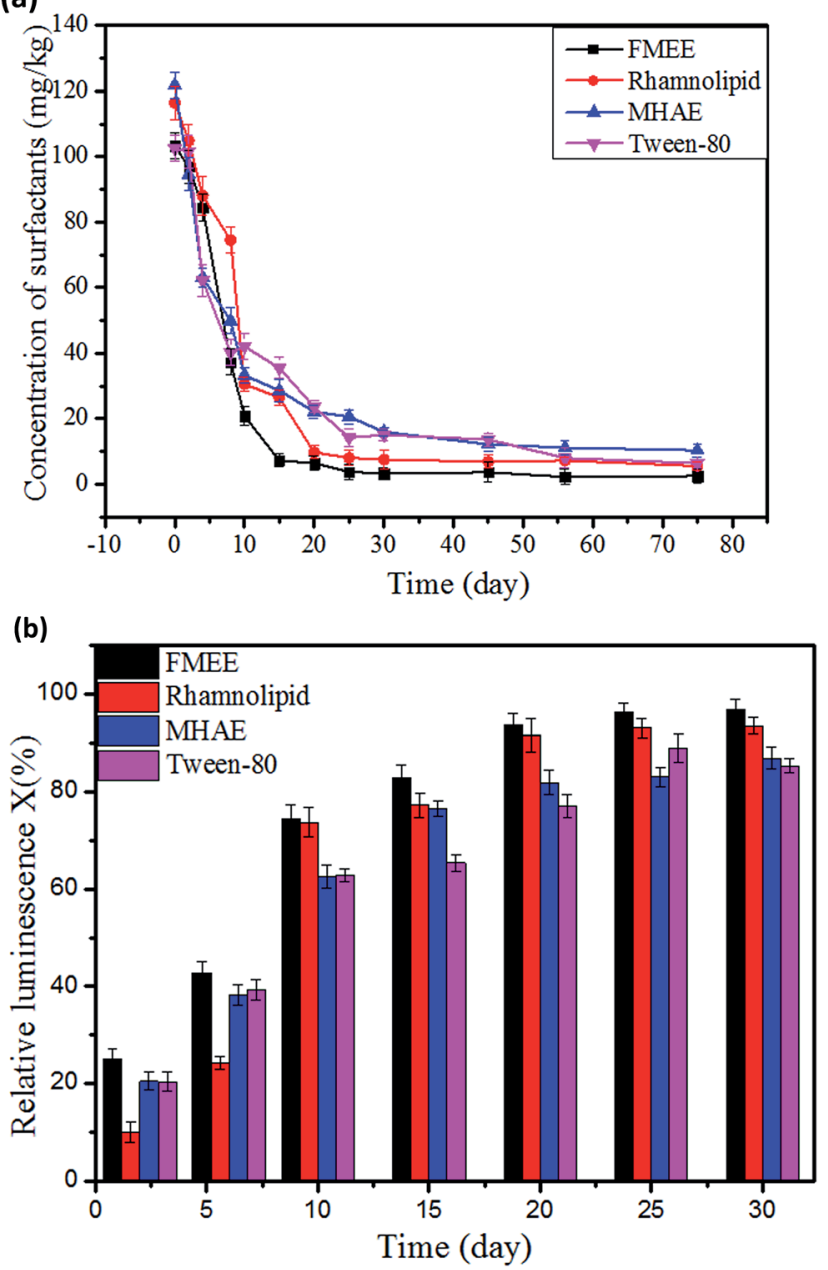

Fig. 3 (a) Concentration levels of surfactants measured during the degradation process. (b) The degradation rate of surfactants in the first 30 days, after which every degradation reached a stable period.

substances detected by GC-MS of MHAE, which were extracted from the soil on the first day of the experiment. After the MHAE had been added into the soil, with the exception of fatty acids, MHAE with different numbers of carbon chains were detected. Thirty days later, most of the MHAE had obviously been consumed, and almost no alcohol ether was found, but several aliphatic acids which degraded more slowly were detected. This may because the scission of alcohol ether led to the production of hydrophobic alkyl groups and polyalkoxylate. ${ }^{26}$ In addition, the growth of microorganisms is also attributed to the quantity of fatty acid in the soil. Moreover, the main type of MHAE remaining in the soil on the $30^{\text {th }}$ day was the MHAE with 12 carbons, and it can be inferred that the $\mathrm{C}_{12}$ alcohol ether cannot degrade as fast as alcohol ether, which with its shorter carbon chain degrades in a short time, or it may be enriched during this period.

With the degradation proceeding, the $\mathrm{C}_{12}$ alcohol ether can be consumed in the later process. 75 days later, compared with Fig. 1 there were almost no telling changes between the control sample and the $75^{\text {th }}$ day's sample. And this may be explained by 


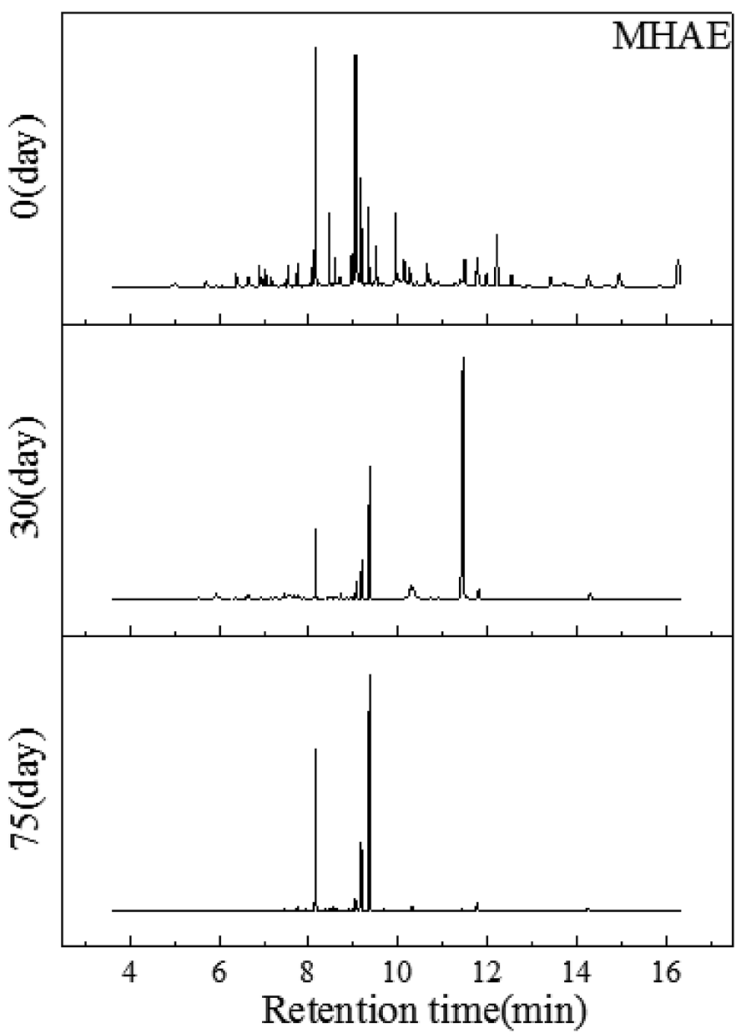

Fig. 4 GC-MS profiles of the MHAE obtained from soil on the first day, the $30^{\text {th }}$ day and the $75^{\text {th }}$ day, respectively.

Table 4 Compounds detected by GC-MS in soil with added MHAE on the first day

\begin{tabular}{ll}
\hline Number & Compounds \\
\hline 1 & Dibutyl phthalate \\
2 & 2-Butoxyethoxy acid, trimethylsilane \\
3 & Hexadecanoic acid, trimethylsilyl ester \\
4 & Octadecanoic acid, trimethylsilyl ester \\
5 & Octadecanoic acid, trimethylsilyl ester \\
6 & $\mathrm{C}_{8}$ alcohol ether \\
7 & $\mathrm{C}_{8}$ alcohol ether \\
8 & Bicyclo[3.2.0]hepta-3,6-diene-1-carbonitrile \\
9 & Eicosenoic acid, trimethylsilyl ester \\
10 & $\mathrm{C}_{8}$ alcohol ether \\
11 & $\mathrm{C}_{12}$ alcohol ether \\
12 & Pyrrole $_{13}$ \\
14 & Docosenoic acid, trimethylsilyl ester \\
15 & $\mathrm{C}_{8}$ alcohol ether \\
17 & $\mathrm{Cycloheptatiene} \mathrm{carbonitrile}_{18}$ \\
19 & $\mathrm{C}_{4}$ alcohol ether \\
& Octadecanoic acid, trimethylsilyl ester \\
\hline
\end{tabular}

the fact that MHAE had been degraded completely. As Carolina C Ang reported, MHAE with different amounts of carbon can be almost totally used up by bacteria in the soil. ${ }^{27}$ This means that the MHAE can be mineralized in soil by microorganisms.

Metabolites in FMEE degradation process over time. As shown in Fig. 3, the mean value of the detected concentration was at a level of $103.3 \mathrm{mg} \mathrm{kg}^{-1}$ in soil, which was slightly lower than the added level of $120 \mathrm{mg} \mathrm{kg}^{-1}$. The primary degradation process focused on the first 15 days, and reached the lowest detected concentration of approximately $3.8 \mathrm{mg} \mathrm{kg}^{-1}$. After that, the mass of FMEE did not express any significant change.

Fig. 5 shows the GC-MS characteristics of the extractions from soil contaminated FMEE after different degradation times. The components detected after FMEE was added into the soil are methyl ester with 16 and 18 carbon chains and aliphatic acids (Table 5). While after 15 days of degradation, most of the methyl ester cannot be detected except for $\mathrm{C}_{16}$ methyl ester. The by-products remaining in the soil were not only parts of the hexadecanoic acid and octadecanoic acid, but some alkanes were generated, such as heneicosane, tetracosane, octacosane and hexacosene. This may because of the consumption of the terminal methyl ester group and microorganism metabolism. Finally, only some fatty acids were left, such as octadecanoic acid and hexadecanoic acid, which inhabited the soil.

At the end of this experiment, only a little of the hexadecanoic acid and octadecanoic acid were found and there was no methyl ester in the soil. Matthew J. Scott had produced a review that explained that the degradation of fatty alcohol ethoxylates begins with the cleavage of the bond between the hydrophobe and hydrophile. ${ }^{26}$ We can infer from Table 4 that

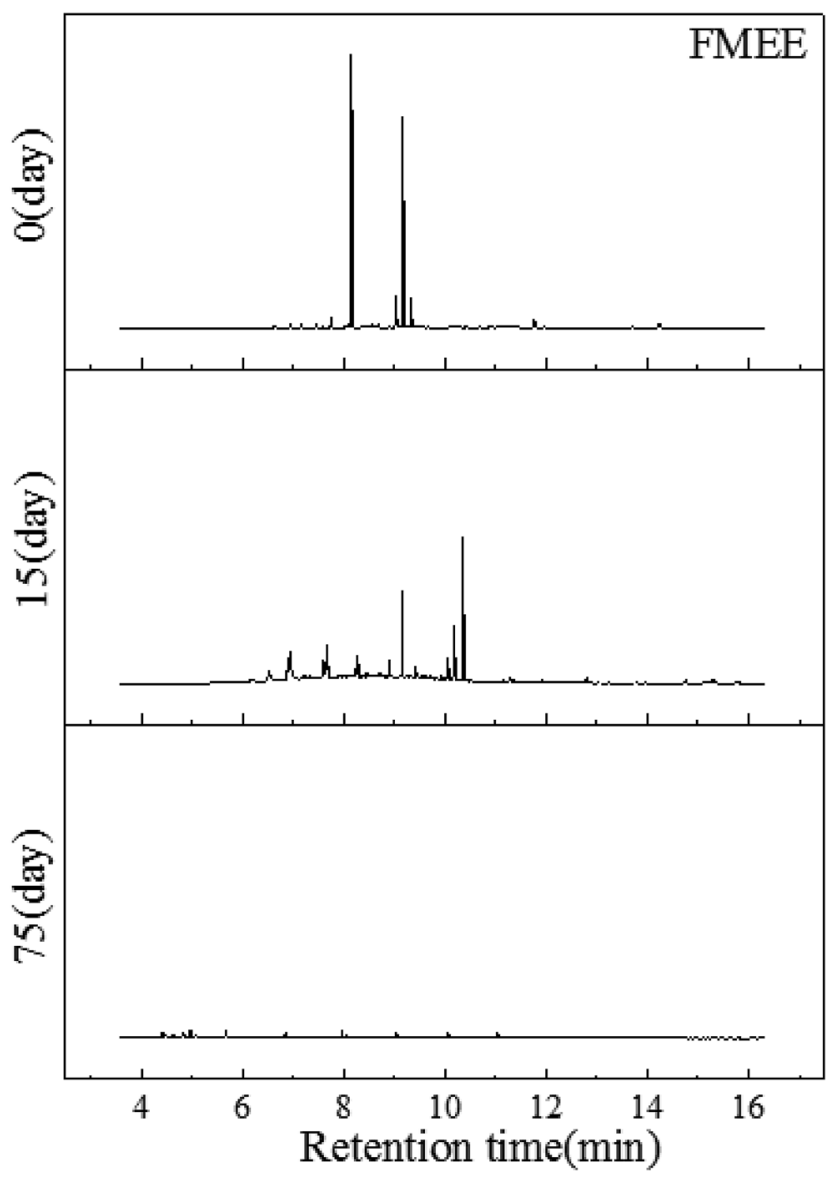

Fig. 5 GC-MS profiles of the FMEE extracted from soil on the first day, the $15^{\text {th }}$ day and the $75^{\text {th }}$ day, respectively. 
Table 5 Compounds detected by GC-MS in soil with added FMEE on the first day

\begin{tabular}{ll}
\hline Number & Compounds \\
\hline 1 & Tetradecanoic acid, trimethylsilyl ester \\
2 & $\mathrm{C}_{16}$ methyl ester \\
3 & $\mathrm{C}_{16}$ methyl ester \\
4 & $\mathrm{C}_{18}$ methyl ester \\
5 & trans-13-Octadecanoic acid, trimethylsilyl ester \\
6 & Octadecanoic acid, trimethylsilyl ester \\
7 & 1-Pentamethyldisilyloxyoctadecane
\end{tabular}

the FMEEs with different carbon chains can be largely consumed.

The methyl group at the end of the FMEE molecule may delay the degradation process. ${ }^{28}$ This result demonstrated that FMEE can be utilized by bacteria in soil. Furthermore, the ester group in the compound is not stable at all, and it can be mineralized at last. ${ }^{29}$

Metabolites in rhamnolipid degradation process over time. The concentration profile of the rhamnolipid degradation process had many fluctuations, and it can be observed that a relatively stable concentration was attained after 20 days of degradation. As with the FMEE, the detected concentration was lower than the added quantity. However, after 20 days of the degradation process, it showed a concentration presence of around $5.54 \mathrm{mg} \mathrm{kg}^{-1}$, although it almost reached the lowest value for the whole process. As shown in Table 6, the main compounds detected by GC-MS in soil with added rhamnolipid were glycolipid and fatty acid with different carbon numbers. Almost all of the quantity of components decreased obviously in the first 20 days. The main remaining substances are hexadecanoic acid and octadecenoic acid, but their quantities decreased. Moreover, hexadecanoic acid and octadecenoic acid had evidently been utilized, and $84.5 \%$ had been degraded during the first 20 days. And after 75 days, $96.14 \%$ of rhamnolipid had been degraded. Wen $\mathrm{Jia}^{30}$ reported that the rhamnolipid degradation process would not be inhibited by the dose of rhamnolipid, but it would be slower at a higher concentration than at a lower one in the first several days when the process was inhibited by the heavy metal Cd and/or $\mathrm{Zn}$ in 20 days. According to the structure of rhamnolipid in Lan, ${ }^{\mathbf{1 8}}$ the rhamnolipid not only has an aliphatic ester but a polysaccharide structure. And thus, after the silicon alkylation reaction, the most likely

Table 6 Compounds detected by GC-MS in soil with added rhamnolipid on the first day

\begin{tabular}{ll}
\hline Number & Compounds \\
\hline 1 & Hexadecanoic acid, trimethylsilyl ester \\
2 & Octadecanoic acid, trimethylsilyl ester \\
3 & Octadecanoic acid, trimethylsilyl ester \\
4 & Propanedioic acid, bis(trimethylsilyl) ester \\
5 & Eicosenoic acid, trimethylsilyl ester \\
6 & Eicosenoic acid, trimethylsilyl ester \\
7 & Hexadecanoic acid, 2,3-bis[(trimethylsilyl)oxy]propyl ester \\
8 & Docosenoic acid, trimethylsilyl ester
\end{tabular}

substances may be the propanedioic acid ester and aliphatic ester. Because the rhamnolipid can be consumed by microorganisms except for its producing bacterium Pseudomonas aeruginosa ${ }^{31}$ the compounds can be utilized by bacteria in soil. ${ }^{32}$ During the first degradation process, most of the rhamnolipid structures were transformed into alkyl acid and a few alkanes with different carbon chains. Tetracosanoic acid, octadecanoic acid (Z)-9-octadecenamide can be also attained. After 75 days of degradation, hexadecanoic acid and octadecenoic acid can be detected in the soil, and we can conclude that hexadecanoic acid and octadecenoic acid may be components of the soil organics or result from cell autolysis. From Fig. 6, we can come to a conclusion that the degradation of rhamnolipid in soil was focused on the first 20 days, and the quantity of each substance declined dramatically.

Metabolites in Tween-80 degradation process over time. The biodegradation process of Tween-80 in soil was analyzed by GCMS, and partial qualitative GC-MS profiles are illustrated in Fig. 7. As shown in Tables 3 and 7, the major compositions extracted from Tween-80 contaminated soil not only contain aliphatic acid and aliphatic alcohol which are constituents in the control soil sample but trans-9-octadecenoic acid and eicosenoic acid which we can infer from the Tween-80 structure. That was because Tween-80 was not a pure substance and the extract underwent a process of silylation derivatization, in

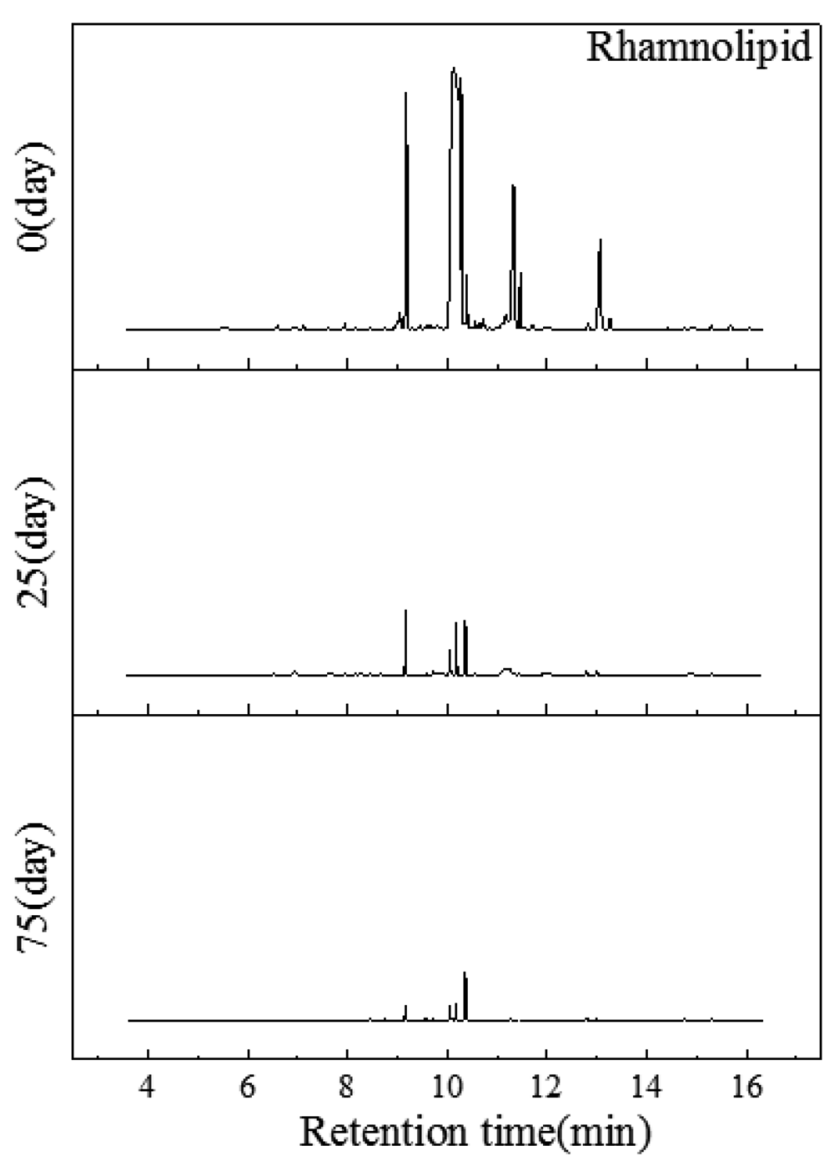

Fig. 6 GC-MS profiles of the rhamnolipid obtained from soil at the first day, the $20^{\text {th }}$ day and the $75^{\text {th }}$ day, respectively. 


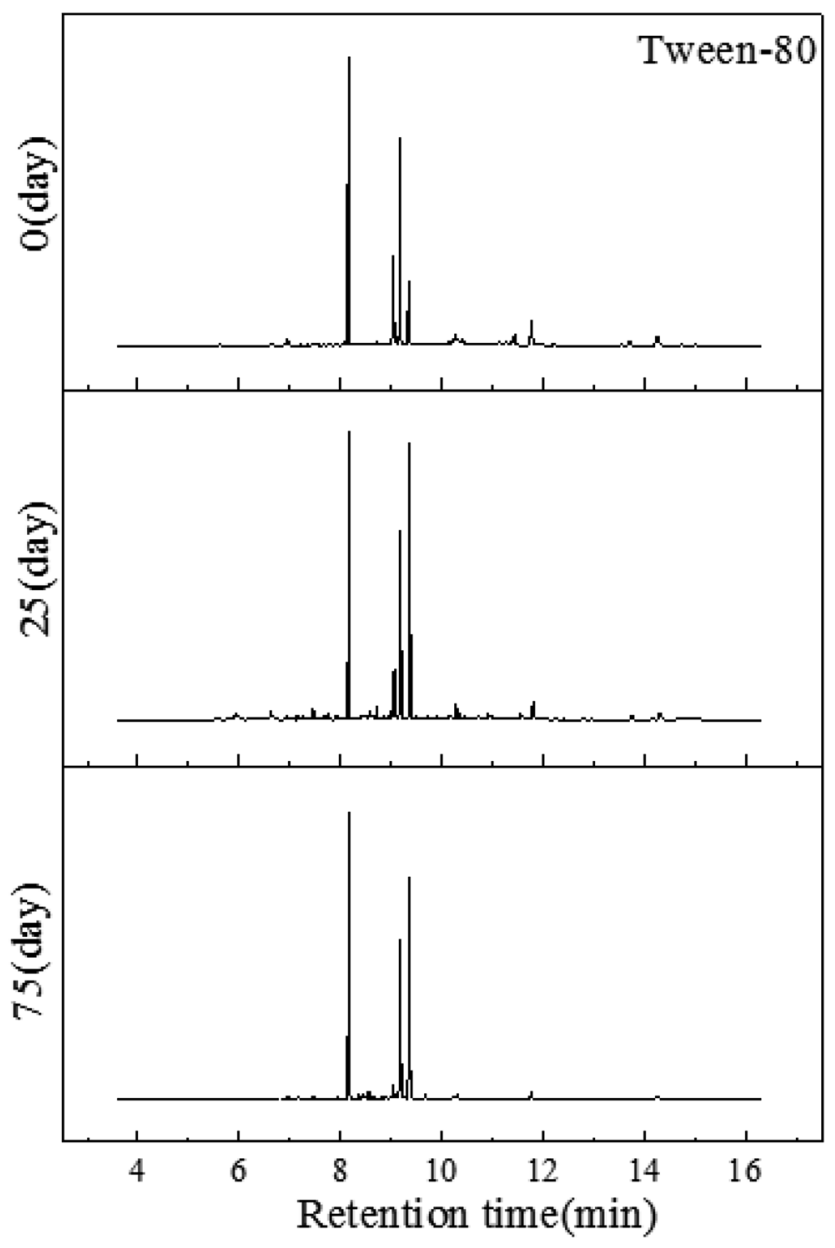

Fig. 7 GC-MS profiles of the Tween-80 extracted on the first day, the $25^{\text {th }}$ day and the $75^{\text {th }}$ day, respectively.

Table 7 Compounds detected by GC-MS in soil with added Tween80 on the first day

\begin{tabular}{ll}
\hline Number & Compounds \\
\hline 1 & Hexadecanoic acid, trimethylsilyl ester \\
2 & Octadecanoic acid, trimethylsilyl ester \\
3 & Octadecanoic acid, trimethylsilyl ester \\
4 & Eicosenoic acid, trimethylsilyl ester \\
5 & Eicosenoic acid, trimethylsilyl ester \\
6 & 2-Monopalmitin trimethylsilyl ester \\
7 & Hexadecanoic acid, propyl ester
\end{tabular}

which Tween-80 reacted with BSTFA/TMCS $(99: 1, \mathrm{v} / \mathrm{v})$. So the structure of Tween- 80 was changed by this reaction and the detected composition were products from derivatization. The octadecenoic and hexadecanoic acid propyl ester had the same aliphatic chain structure compared with Tween-80. It can be inferred that these compounds may be the derived products. It has been reported that octadecenoic acid can be degraded by bacteria which have been isolated from soil. ${ }^{32}$ As Fig. 7 shows, after the first 25 days, most of the aliphatic acid ester and alcohol had decreased, which means that a large proportion of Tween-80 was reduced during this period. But some aliphatic acids, such as hexadecanoic acid and octadecenoic acid, still remained. During the degradation period, $(Z)$-9-tricosene was produced in the soil. This can be explained by the fact that the polyoxyethylene sorbitan was consumed firstly in the Tween-80 structure. At the same, eicosanoic acid and oleic acid can be formed because of the bacterial metabolism.

However, after the degradation process, the monostearin in the soil did not show any dramatic decrease. And fatty acids and fatty acid methyl esters can be detected in the soil after 75 days. This demonstrated that the degradation of hexadecanoic acid and octadecenoic acid were much slower. The substances remaining in the soil after 75 days were similar to those of the control, from which we can infer that the degradation process of Tween-80 does not do any harm to the soil environment. This is coincident with the research carried by Lee in $2013 .^{33}$

\section{Toxicity of surfactants}

Surfactants are organic polymers which are more or less toxic to microorganisms. Their toxicity depends on their structures, as Rebello reported. ${ }^{34}$ The biotoxicity of the surfactants was assayed by using luminescent bacteria. Fig. 8(a) shows the acute toxicity

(a)

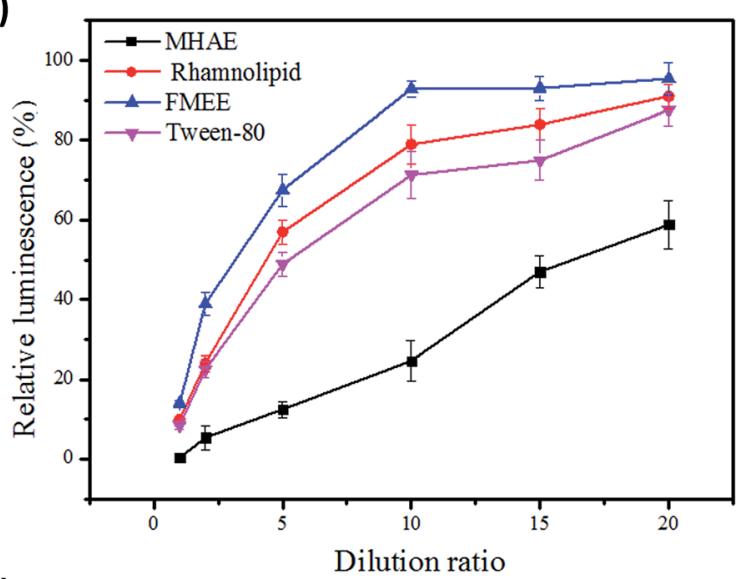

(b)

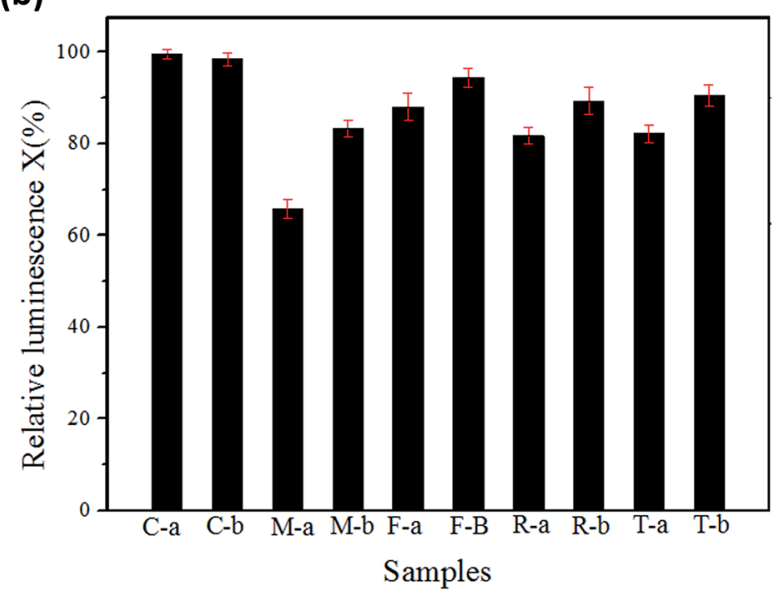

Fig. 8 (a) Relative luminescence of surfactants at different dilution ratios. (b) The relative luminescence of soil samples. $C$ means the control sample, "a" stands for before the degradation process and " $b$ " stands for the end of experiment. M, F, T and R mean the FMEE, MHAE, Tween-80 and rhamnolipid, respectively. 
of the surfactants at different dilution ratios. The surfactants stock solution had a relative luminescence lower than $20 \%$, and the acute toxicity of the surfactants was observed when the concentration reached $50 \mathrm{mg} \mathrm{\textrm {L } ^ { - 1 }}$. The relative luminosities of MHAE, FMEE, Tween-80 and rhamnolipid were 50.8\%, 80.6\%, $70.2 \%$ and $78.6 \%$, respectively, when $50 \mathrm{mg} \mathrm{L}^{-1}$ surfactants solutions were applied in the determination. Compared with other surfactants, FMEE had the lowest toxicity, followed by rhamnolipid, Tween-80 and MHAE. This toxicity result well explained why FMEE has the shortest lay phase and the highest degradation rate, as shown in Fig. 2 and 3. Fig. 8(b) shows the acute toxicity of soil suspensions containing different surfactants at the beginning and the end of the experiment. It can be seen that the control groups are not toxic to luminescent bacteria. However, the addition of surfactants into the soil decreased the shining of the luminescent bacteria to some extent, but when the degradation was complete, the relative luminescence of the samples was raised. This means that the acute toxicity declined as the degradation proceeded. On the other hand, the addition of MHAE decreased the relative luminescence dramatically, whereas it increased with the degradation process. We can infer that the biodegradation process of MHAE may produce somewhat less harm to microorganisms or the soil, but the higher residual MHAE inhibits the luminescence more.

\section{Conclusions}

In this work, the biodegradation processes of MHAE, FMEE, Tween-80 and rhamnolipid in a soil environment were investigated. The biodegradation process in soil lasted for 75 days under natural conditions varying from $15{ }^{\circ} \mathrm{C}$ to $22{ }^{\circ} \mathrm{C}$ in the autumn in southwest of China. Finally, all four surfactants degraded to different extents. FMEE showed the most effective process, and was degraded to $2.4 \%$ of the initial concentration. And rhamnolipid, Tween-80 and MHAE followed in that order. Furthermore, most of the reduction of surfactant was due to mineralization according to the GC-MS characterization of each surfactant. Meanwhile, with the increase in the number of bacteria, most of the surfactants were degraded. The biodegradation processes depended on the consumption of surfactant by bacteria. For all of the surfactants studied can be used as carbon sources for the growth of microorganisms. Finally, all the results indicated that FMEE had the fastest rate of degradation among all the surfactants in soil. For this reason, FMEE is superior to the other three surfactants. Less harm will occur because of its lower toxicity to the environment and the lower possibility of it being scoured into water by rain. Through this investigation, it can be inferred that the biosurfactant rhamnolipid is not superior in terms of acute toxicity or in its ability to biodegrade. Factors that affect the utilization of surfactants should not only take the ability to biodegrade into consideration because it is the same or less compared with synthetic surfactants.

\section{Acknowledgements}

This work was financially supported by the Open Projects of Key Laboratory of Oil \& Gas Applied Chemistry of Sichuan Province,
Southwest Petroleum University, PR China (YQKF201406), Open Projects of Key Laboratory of Development and Application of Rural Renewable Energy, Ministry of Agriculture, PR China. China National Petroleum Corporation Key $S$ \& $T$ Special Projects of the development of large oil-gas fields and coalbed methane (Grant No. 2016ZX05040-003) and Xinjiang Oilfield Company No. 1 Gas Production Plant.

\section{References}

1 N. S. Neta, J. A. Teixeira and L. R. Rodrigues, Crit. Rev. Food Sci. Nutr., 2015, 55, 595-610.

2 K. C. Taylor and H. A. Nasr-EL-Din, Colloids Surf., A, 1996, 108(1), 49-72.

3 K. Urum, S. Grigson, T. Pekdemir and S. McMenamy, Chemosphere, 2006, 62, 1403-1410.

4 T. M. Bo Gejlsbjerg and T. T. Andersen, Chemosphere, 2003, 50, 321-331.

5 W. Zhang, D. C. Tsang and I. M. Lo, Chemosphere, 2007, 66, 2025-2034.

6 M. T. Ammami, F. Portet-Koltalo, A. Benamar, C. DuclairoirPoc, H. Wang and F. Le Derf, Chemosphere, 2015, 125, 1-8.

7 P. Guo, W. Chen, Y. Li, T. Chen, L. Li and G. Wang, Environ. Sci. Pollut. Res. Int., 2014, 21, 1370-1379.

8 C. Yuan and C. H. Weng, Chemosphere, 2004, 57, 225-232.

9 M. Lechuga, M. Fernandez-Serrano, E. Jurado, J. Nunez-Olea and F. Rios, Ecotoxicol. Environ. Saf., 2016, 125, 1-8.

10 B. L. Tenside, J. Surfactants Deterg., 1989, 26, 101-107.

11 C. J. Tang, P. Zheng, T. T. Chen, J. Q. Zhang, Q. Mahmood, S. Ding, X. G. Chen, J. W. Chen and D. T. Wu, Water Res., 2011, 45, 201-210.

12 S. Jiao, S. Zheng, D. Yin, L. Wang and L. Chen, Chemosphere, 2008, 73, 377-382.

13 A. Karci, I. Arslan-Alaton and M. Bekbolet, J. Hazard. Mater., 2013, 263(2), 275-282.

14 M. I. Bautista-Toledo, J. Rivera-Utrilla, J. D. Mendez-Diaz, M. Sanchez-Polo and F. Carrasco-Marin, J. Colloid Interface Sci., 2014, 418, 113-119.

15 J. Jensen, Sci. Total Environ., 1999, 226, 93-111.

16 B. Brycki, M. Waligorska and A. Szulc, J. Hazard. Mater., 2014, 280, 797-815.

17 M. D. Coello, C. A. Aragon, R. Rodriguez-Barroso, et al., Environ. Technol., 2009, 30, 1391-1396.

18 G. Lan, Q. Fan, Y. Liu, C. Chen, G. Li, Y. Liu and X. Yin, Biochem. Eng. J., 2015, 101, 44-54.

19 R. W. Jackson, K. Osborne, G. Barnes, C. Jolliff, D. Zamani, B. Roll, A. Stillings, D. Herzog, S. Cannon and S. Loveland, Appl. Environ. Microbiol., 2000, 66, 453-454.

20 M. M. Gonzalez, J. Martin, D. Camacho-Munoz, J. L. Santos, I. Aparicio and E. Alonso, Waste Manage., 2012, 32, 13241331.

21 K. A. G. Michel Dubois, J. K. Hamilton, P. A. Rebers and F. Smith, Anal. Chem., 1956, 28, 250-256.

22 D. G. Brown and P. R. Jaffeä, Environ. Sci. Technol., 2001, 35, 2022-2025.

23 A. Leyva, A. Quintana, M. Sanchez, E. N. Rodriguez, J. Cremata and J. C. Sanchez, Biologicals, 2008, 36, 134-141. 
24 M. Castillo, E. Martínez, D. Barceló, A. Ginebreda and L. Tirapu, Analyst, 2000, 125, 1733-1739.

25 Y. Yang, H. Li, J. Zhang, N. Sun and H. Sun, Food Anal. Methods, 2013, 7, 798-805.

26 M. N. J. Matthew and J. Scott, Biochim. Biophys. Acta, 2000, 1508, 235-251.

27 C. C. Ang and A. S. Abdul, J. Hydrol., 1992, 138, 191-209.

28 H. S. I. Hama, T. Tamura, T. Nakamura and K. Miura, J. Surfactants Deterg., 1998, 1, 93-97.

29 K. H. Kim and W. H. Jo, Macromol. Res., 2008, 16, 749-752.
30 J. Wen, S. P. Stacey, M. J. McLaughlin and J. K. Kirby, Soil Biol. Biochem., 2009, 41, 2214-2221.

31 G. Zeng, H. Fu, H. Zhong, X. Yuan, M. Fu, W. Wang and G. Huang, Biodegradation, 2007, 18, 303-310.

32 N. Frank, A. Lissner, M. Winkelmann, R. Huttl, F. O. Mertens, S. R. Kaschabek and M. Schlomann, Biodegradation, 2010, 21, 179-191.

33 S. Lee, J. H. Kweon and H. S. Kim, Int. Biodeterior. Biodegrad., 2013, 85, 652-660.

34 S. Rebello, A. K. Asok, S. Mundayoor and M. S. Jisha, Environ. Chem. Lett., 2014, 12, 275-287. 